\title{
Smoked Cocaine Self-Administration is Decreased by Modafinil
}

\author{
Carl L Hart ${ }^{*, 1,2}$, Margaret Haney', Suzanne K Vosburg', Eric Rubin' and Richard W Foltin' \\ 'Division on Substance Abuse, New York State Psychiatric Institute and Department of Psychiatry, College of Physicians and Surgeons of \\ Columbia University, New York, NY, USA; ²Department of Psychology, Columbia University, New York, NY, USA
}

\begin{abstract}
Modafinil has been reported to reduce cocaine use in a clinical sample of infrequent users (2 days/week), but the effects of modafinil on cocaine self-administration in the laboratory have not been studied. The present study investigated the effects of modafinil maintenance on cocaine self-administration by frequent users (4 days/week) under controlled laboratory conditions. During this 48-day double-blind, crossover design study, the effects of modafinil maintenance $(0,200$, and $400 \mathrm{mg} /$ day) on response to smoked cocaine $(0,12,25$, and $50 \mathrm{mg}$ ) were examined in nontreatment-seeking cocaine-dependent individuals $(n=8)$. Cocaine significantly increased selfadministration, subjective-effect ratings, and cardiovascular measures; modafinil at both doses (200 and 400 mg/day) markedly attenuated these effects. These findings agree with data from previous human laboratory and clinical investigations of modafinil as a potential cocaine abuse treatment medication. Thus, our data support the potential of modafinil as a pharmacotherapy for cocaine dependence. Neuropsychopharmacology (2008) 33, 76I-768; doi:I0.I038/sj.npp. I30 I472; published online I3 June 2007
\end{abstract}

Keywords: cocaine; choice; modafinil; Provigil ${ }^{\mathbb{R}}$; pharmacotherapy; humans; mood

\section{INTRODUCTION}

In the United States, each year greater than one quarter of the 2.4 million current cocaine users seek treatment for cocaine-related problems (SAMHSA, 2006). Despite the fact that the number of cocaine treatment seekers is similar to the number of individuals seeking treatment for heroin dependence (for which there are several approved pharmacotherapeutic options), currently there is no approved cocaine abuse pharmacotherapy. For at least two decades, intense research efforts have focused on elucidating the underlying neuronal mechanisms of cocaine-related effects in an effort to identify targets for potential pharmacotherapies. Much of these efforts have concentrated on influencing the activity of midbrain dopaminergic neurons, with disappointing results (for review, see Hart and Lynch, 2005). Because cocaine exerts multiple central nervous system (CNS) effects, including transporter blockade of several monoamine transmitters, some have suggested that the low success rate is not surprising given the relatively narrow and oversimplified previous focus (eg Bardo, 1998; Hart and Lynch, 2005).

Modafinil, approved to promote wakefulness in patients with excessive daytime sleepiness, has received recent

*Correspondence: Dr CL Hart, Department of Psychiatry, New York State Psychiatric Institute at Columbia University, 1051 Riverside Drive, Unit 120, New York, NY 10032, USA, Tel: + I 2125435884 , Fax: + I 212543 599।, E-mail: clh42@columbia.edu

Received 6 April 2007; revised 9 May 2007; accepted II May 2007 research attention as a potential cocaine abuse treatment medication. While the neurochemical mechanisms underlying modafinil's therapeutic actions remain unresolved, the drug has been demonstrated to occupy both the dopamine and norepinephrine transporter at clinically relevant doses (Mignot et al, 1994; Madras et al, 2006). Its affinity for the norepinephrine transporter, however, is approximately $50 \%$ lower than it is for the dopamine transporter (Madras et al, 2006). A prominent hypothesis regarding the neurochemical basis of modafinil-associated therapeutic actions proposes that they are due to the drug's ability to increase dopaminergic activity, which stimulates adrenergic receptors in the prefrontal cortex (Wisor and Eriksson, 2005). This perspective is supported by data showing that the wake-promoting effects of the drug are blocked by $\alpha_{1}$ antagonists (eg Duteil et al, 1990; Lin et al, 1992) but are unaltered by dopamine antagonists (Lin et al, 1992) or lesions of the noradrenergic projections from the locus coeruleus to the forebrain (Wisor and Eriksson, 2005). Alternatively, others have suggested that modafinil-associated therapeutic effects are due to its ability to enhance glutamate release and inhibit $\gamma$-aminobutyric acid (GABA) release (Ferraro et al, 1997a, b, 1999). Despite the lack of consensus regarding modafinil's precise mechanism of action, it is clear that many of its neurochemical actions overlap with those of cocaine. This overlap might provide clues about the mechanism(s) mediating the recent report of positive outcome when modafinil was tested as a potential treatment for cocaine abuse (Dackis et al, 2005). 
Based on encouraging results from their laboratory investigation of modafinil as a potential cocaine abuse treatment medication, Dackis et al (2005) conducted a larger, follow-up clinical trial in which cocaine use, as measured by urine toxicology, was the primary outcome measure. During this 8-week study, cocaine-dependent participants were randomized to receive either placebo or $400 \mathrm{mg} /$ day modafinil. Modafinil significantly reduced the number of cocaine-positive urine samples obtained compared with placebo. While this finding is encouraging, it should be interpreted within the confines of a few important potential limitations. For example, relative to participants in the control group, individuals in the modafinil group reported using cocaine on fewer days (3vs 2) and had more negative cocaine urine samples at baseline $(\sim 20 v s \sim 40 \%)$. Together, these factors potentially influenced the study outcome.

Nevertheless, findings from two laboratory studies of human cocaine abusers also support the utility of modafinil as a treatment medication for cocaine abuse (Dackis et al, 2003; Malcolm et al, 2006). The first report was a withinsubjects laboratory investigation, during which seven cocaine-dependent individuals were maintained on modafinil (placebo, 200, and $400 \mathrm{mg} /$ day) for 4 days before receiving open-label cocaine $(30 \mathrm{mg})$ i.v. (Dackis et al, 2003). Physiological and subjective measures were assessed repeatedly after cocaine administration. Both active modafinil doses markedly reduced cocaine-related ratings on the Addiction Research Center Inventory Amphetamine scale, which was interpreted as a blunting of cocaine-induced euphoria. Malcolm et al (2006) replicated this finding and also reported that modafinil attenuated cocaine-induced heart rate (HR) and systolic blood pressure elevations.

It is important to note, however, that previous laboratory investigations of potential cocaine abuse treatment medications have shown reductions in cocaine-related subjective effects without corresponding decreases in cocaine selfadministration. For example, data from this laboratory demonstrated that gabapentin, a nonselective GABA agonist, significantly attenuated cocaine-induced euphoria, but did not alter cocaine self-administration (Hart et al, 2004). This finding is consistent with results from subsequent laboratory studies and an outpatient, double-blind clinical trial evaluating gabapentin for utility in treating cocaine dependence (Hart et al, 2007a, b; Bisaga et al, 2006). These observations emphasize the potential utility of assessing a measure of cocaine-taking behavior when evaluating potential pharmacotherapies for cocaine dependence. In this way, the likelihood of obtaining false-positive results is substantially reduced.

Given the above considerations and the increasing interest in modafinil as a potential cocaine abuse pharmacotherapy (Vocci and Ling, 2005; Sofuoglu and Kosten, 2006), we felt further study of this medication for cocaine dependence was warranted. Thus, the present 48-day inpatient/outpatient study examined the effects of oral modafinil maintenance $(0,200,400 \mathrm{mg} /$ day $)$ on smoked cocaine self-administration in a group of nontreatmentseeking cocaine-dependent volunteers, who reported using cocaine, on average, 4 days weekly. Cocaine-associated cardiovascular and subjective effects were also assessed during modafinil treatment. We hypothesized that cocaine self-administration and subjective effects would be decreased as a function of modafinil maintenance condition. Although we assumed the cocaine-modafinil combination would be well tolerated, no prediction was made regarding the impact of modafinil maintenance on cocaine-induced cardiovascular effects because inconsistent results had been previously reported, that is, Dackis et al (2003) reported modafinil produced no significant effects, whereas Malcolm et al (2006) reported the drug decreased some cocaineevoked cardiovascular effects.

\section{METHODS}

\section{Participants}

Eight black research volunteers (seven males, one female) with a mean age of $38.5 \pm 2.8( \pm S D)$ completed this study. They were solicited via word-of-mouth referral and newspaper advertisements in New York City, and each signed a consent form that was approved by the Institutional Review Board of The New York State Psychiatric Institute. Before study enrollment, participants passed comprehensive medical and psychiatric evaluations (including a Structured Clinical Interview for Diagnostic and Statistical Manual of Mental Disorders (DSM-IV SCID)) and were within normal weight ranges according to the 1983 Metropolitan Life Insurance Company height/weight table (body mass index, $24.3 \pm 1.5)$. All met DSM-IV criteria for current smoked cocaine dependence and stated they were not seeking treatment for cocaine dependence at the time of study participation. No participant met criteria for any other axis I disorder. They reported currently using cocaine $4.1 \pm 1.6$ (mean \pm SD) days per week and spending $\$ 275 \pm 109$ (mean \pm SD) per week on the drug (the current cost of street cocaine in the New York City area is \$25-40 per gram). On average, participants reported using cocaine for $19.8 \pm 6.6$ (mean $\pm S D$ ) years. Five participants reported current alcohol use (0.5-18 drinks per week), five reported current marijuana use (1-5 times per week), and five smoked 5-30 tobacco cigarettes per day. Other reported drug use was infrequent. Urine toxicology analyses during the screening process showed that all participants tested positive for the cocaine metabolite and two tested for the marijuana metabolite. The participants had completed $11.75 \pm 1.9$ (mean $\pm S D$ ) years of education.

Five additional male participants (four black, one Hispanic) began, but did not complete the protocol; one had an abnormal electrocardiogram before receiving cocaine (this participant was receiving placebo modafinil), one was arrested during the outpatient portion of the study, one developed a rash while being maintained on placebo modafinil, one failed to meet his admissions appointment, and one left the study for personal reasons. Thus, no early dropouts were specifically due to side effects from modafinil.

\section{Design and Procedures}

During this within-subjects, alternating in-patient/outpatient 48-day study, participants were maintained on modafinil (placebo, 200, and $400 \mathrm{mg} /$ day) and four doses of smoked cocaine $(0,12,25$, and $50 \mathrm{mg})$. They were each 
tested twice under each modafinil condition (Table 1). The first participant completed almost the entire study (43 days) on an in-patient basis to evaluate the effects of modafinil in combination with cocaine before providing other participants with modafinil on an outpatient basis. The remaining participants were maintained as in-patients and outpatients alternately over 48 days (for a total of 23 in-patient days per participant). All cocaine self-administration testing occurred during in-patient days. Initially, participants were admitted to the Irving Center for Clinical Research (New York Presbyterian Hospital) for 3 days and modafinil maintenance (placebo, 200, or $400 \mathrm{mg}$ ) was initiated. Modafinil was administered in a double-blind fashion throughout the study, but, for safety reasons, the 200-mg condition always preceded the 400-mg condition. Four participants received placebo first, and the other four received modafinil first. Subsequently, the modafinil maintenance dose was continued on an outpatient basis for 4 days. Then, participants were in-patient for 8 days; during 4 of those days, smoked cocaine-related effects $(0,12,25$ and $50 \mathrm{mg}$ ) were assessed in the presence of the modafinil maintenance dose. Each cocaine dose was tested twice per maintenance condition (see Table 1). The in-patient days following cocaine testing were used for crossover to another modafinil condition. Subsequently, the modafinil maintenance dose was continued on an outpatient basis for 6 days and then, the 8-day in-patient phase was repeated. After crossing over to a different maintenance condition, participants were maintained on an outpatient basis for 6 days, followed by the final 8-day in-patient phase. The final 5 days of the study were used to taper off modafinil.

During the outpatient phases of this study, participants came to the laboratory every $2-3$ days, during which time they (1) were assessed for the emergence of side effects, (2) received study medication, and (3) gave an observed urine sample, which was examined for the presence of the riboflavin marker and drugs of abuse. Modafinil and placebo capsules were filled with powdered riboflavin

Table I Experimental Timeline

\begin{tabular}{lll}
\hline Study day & Location & Phase \\
\hline $1-3$ & In-patient & Initial placebo/modafinil dosing \\
$4-7$ & Outpatient & Placebo/modafinil maintenance \\
$8-10$ & In-patient & Maintenance \\
$11-12$ & In-patient & First cocaine dose-response \\
$14-15$ & In-patient & Second cocaine dose-response \\
15 & In-patient & Medication crossover \\
$16-21$ & Outpatient & Placebo/modafinil maintenance \\
$22-24$ & In-patient & Maintenance \\
$25-26$ & In-patient & First cocaine dose-response \\
$28-29$ & In-patient & Second cocaine dose-response \\
29 & In-patient & Medication crossover \\
$30-35$ & Outpatient & Placebo/modafinil maintenance \\
$36-38$ & In-patient & Maintenance \\
$39-40$ & In-patient & First cocaine dose-response \\
$42-43$ & In-patient & Second cocaine dose-response \\
$44-48$ & Outpatient & Taper off medication \\
\hline
\end{tabular}

(fluoresces when urine is exposed to ultraviolet light) to monitor compliance with the dosing regimen. Blood was drawn to measure plasma modafinil levels once during each outpatient period. Participants were given $\$ 15$ in cash at each outpatient visit, and received $\$ 15$ in merchandise vouchers for each riboflavin-positive urine sample. Merchandise vouchers were redeemable at local stores.

\section{Apparatus}

During sessions, each participant sat in a reclining lounge chair facing a computer monitor, which displayed subjective-effects questionnaires. A response manipulandum ('mouse') was used for completion of subjective-effects questionnaires. For blood withdrawal, an 18-gauge catheter (Quik-Cath ${ }^{\circledR}$, Travenol Laboratories, Deerfield, IL) was inserted in a subcutaneous arm vein. The i.v. line was kept patent by a physiological saline solution drip at a rate of $2 \mathrm{cc} / \mathrm{min}$. The electrocardiogram was continuously monitored via chest electrodes (Tektronix 413 Monitor ${ }^{\circledR}$, Beaverton, OR; MAC PC ${ }^{\circledR}$, Marquette Electronics, Milwaukee, WI), while HR and blood pressure (systolic, SP; diastolic, DP) were recorded every 2 min (Sentry II, Model 6100 automated vital signs monitor, NBS Medical, Costa Mesa, CA) beginning 20 min before drug administration. An Apple Macintosh computer located in an adjacent room was used for automated data collection.

\section{Procedure}

While in-patient, participants had access to television, radio, telephone, videotaped movies, and tobacco cigarettes when not participating in a session. They could not leave the unit unescorted by research staff and could not receive visitors.

Each participant completed a total of $24,2.5$-h weekday laboratory sessions; two sessions were conducted per day on study days $11,12,14,15,25,26,28,29,39,40,42$, and 43. During sessions, research nurses located in the adjacent room continuously observed participants through a oneway mirror, and communication was possible via an intercom system. Sessions occurred under all three modafinil conditions (placebo, 200, and $400 \mathrm{mg} /$ day).

Sessions started at approximately 0900 and 1300, and began with a 30-min baseline measurement of cardiovascular activity and mood. At the start of each session, participants were provided with $\$ 25$ from their study earnings (five $\$ 5$ bills, one for each choice opportunity). Then, they were allowed to smoke the 'sample' dose of cocaine base $(0,12,25$, and $50 \mathrm{mg})$ available that session. Cocaine smoking was accomplished by placing a metered dose of cocaine base in an $8 \mathrm{~cm}$ glass tubing, or 'stem,' packed with fine metal mesh; participants held the glass stem while the research nurse applied the flame from a lighter until the individual had finished inhaling the volatized cocaine. Participants were blindfolded during inhalation to decrease potential expectancy effects. Following the sample dose, participants were given five opportunities, at 14-min intervals, to purchase the same amount of cocaine as in the sample dose or to keep $\$ 5$ for that choice opportunity. A cocaine dose was not given on any trial in which cardiovascular activity was above our criteria for safe 
drug administration. Cardiovascular criteria for withholding a dose were as follows: (1) SP $>160 \mathrm{~mm} \mathrm{Hg}$, sustained for longer than $6 \mathrm{~min}$ (ie $>3$ consecutive readings); or (2) $\mathrm{DP}>100 \mathrm{~mm} \mathrm{Hg}$, sustained for longer than $6 \mathrm{~min}$ (ie $>3$ consecutive readings); or (3) $\mathrm{HR}>220$, participant's age $\times 0.85$ b.p.m., sustained for $6 \mathrm{~min}$ (ie three consecutive readings). Under each modafinil maintenance condition, the four available cocaine doses $(0,12,25$, and $50 \mathrm{mg})$ were tested in four self-administration sessions (morning and afternoon) over 2 days, and then the procedure was repeated on 2 of the following 3 days. Thus, each cocaine dose was tested twice under each modafinil maintenance condition, with dosing order systematically varied.

\section{Subjective-Effects Questionnaire}

A subjective-effects questionnaire was completed at baseline, 4 min following delivery of the selected option (cocaine or \$5) and $30 \mathrm{~min}$ following the last selected option of the session. The questionnaire consisted of a series of $10-\mathrm{cm}$ visual analog scales (VAS). To reduce the number of dependent variables, cluster analysis was accomplished as previously described (Evans et al, 2002; Foltin and Haney, 2004), and each cluster score was derived by taking the arithmetic average of the items in the cluster. Five clusters were produced from 20 VAS items: (1) Bad Drug Effects consisted of seven items: 'anxious,' 'bad drug effect,' 'confused,' 'depressed,' 'irritable,' 'sedated,' and 'tired'; (2) Self-Esteem consisted of five items: 'alert,' 'friendly,' 'selfconfident,' 'social,' and 'talkative'; (3) Calm consisted of two items: 'calm,' and 'able to concentrate'; (4) Good Drug Effect consisted of three items: 'good drug effect,' 'high,' and 'stimulated'; and (5) Drug Quality consisted of three items: 'the choice was of high quality,' 'the choice was potent,' and 'I liked the choice.' Three VAS items were used to operationalize drug craving: 'I want cocaine,' 'I want alcohol,' and 'I want nicotine.' A final question asked individuals 'How much would you pay for the dose you just received?' with a scale range of $\$ 0-25$.

\section{Plasma Analysis}

Blood samples for the analysis of cocaine levels were drawn three times during each laboratory session: (1) before cocaine administration, (2) $4 \mathrm{~min}$ after the first cocaine dose, and (3) $4 \mathrm{~min}$ after receipt of the last selected (cocaine or money). All blood samples were analyzed for cocaine and cocaine metabolites (Isenschmid et al, 1992). In addition, blood samples were drawn for modafinil levels twice per inpatient week. To monitor compliance with outpatient medication regimens, modafinil levels were also assessed in weekly blood samples drawn during the outpatient phases of the study. Laboratory analyses were carried out by the Analytical Toxicology Laboratory at New York State Psychiatric Institute.

\section{Cocaine and Study Medication}

Cocaine free-base was prepared by the New York State Psychiatric Institute Pharmacy (Foltin et al, 1990). Modafinil $(100 \mathrm{mg})$ tablets were packaged into size \#00 opaque capsules with riboflavin filler by the New York State
Psychiatric Institute Pharmacy. Identical placebo capsules contained only lactose and riboflavin filler. During the inpatient phases, modafinil was administered as two identical capsules at 0700 and 1900 each day on the research unit. During outpatient phases, participants were instructed to follow the same dosing regimen.

\section{Data Analysis}

Repeated measures analyses of variance with cocaine dose $(0,12,25$, and $50 \mathrm{mg})$, modafinil maintenance condition (placebo, 200, and $400 \mathrm{mg} /$ day) and replication (first and second under each maintenance condition) as withinsubjects factors were conducted to examine differences in mean cocaine choice selection and peak values for subjective and cardiovascular effects. Planned contrasts were calculated comparing results from placebo maintenance to the results obtained under active modafinil maintenance for each cocaine dose. The planned contrasts were single-degree-of-freedom comparisons that used the error term for the medication $\times$ cocaine dose interaction. Active or placebo cocaine was administered on 440 dosing occasions. When the cocaine dose was withheld, participants still completed the subjective-effects ratings and cardiovascular monitoring continued, and the data obtained, even though cocaine was not administered, were used in the analyses. In addition, because modafinil maintenance order was not entirely random, maintenance order was analyzed as a covariant; no significant effects of order were detected for any of the dependent variables. Data were considered statistically significant at $p<0.05$, using Huynh-Feldt corrections where appropriate.

\section{RESULTS}

Active or placebo cocaine was purchased 446 times, with only six doses not given because of elevated cardiovascular measures. All six doses were withheld under the placebo modafinil maintenance condition. Doses were more likely to be withheld when the higher cocaine doses were available: one withheld when $12 \mathrm{mg}$ was available, two withheld when $25 \mathrm{mg}$ was available, and three withheld when $50 \mathrm{mg}$ was available.

\section{Self-Administration}

Figure 1 (left panel) shows the number of purchased cocaine doses as a function of cocaine dose and modafinil maintenance condition. Active cocaine was purchased significantly more than placebo cocaine $(F(3,42)=15.62$, $p<0.001$ ), participants purchased about 2,4 , and 4.5 doses when the 12-, 25-, and 50-mg dose was available, respectively. Relative to placebo, both active modafinil maintenance conditions significantly decreased cocaine purchases of the two larger doses ( 25 and $50 \mathrm{mg}, p<0.03$ for both maintenance conditions).

\section{Subjective Effects}

Cocaine produced dose-dependent increases in ratings on the Good Drug Effect cluster $\mathrm{F}_{(3,42)}=19.85, p<0.001$; the Drug Quality cluster (Figure 2, left panel), $\left.\mathrm{F}_{(3,42}\right)=16.43$, $p<0.001$; and how much participants were willing to pay for 


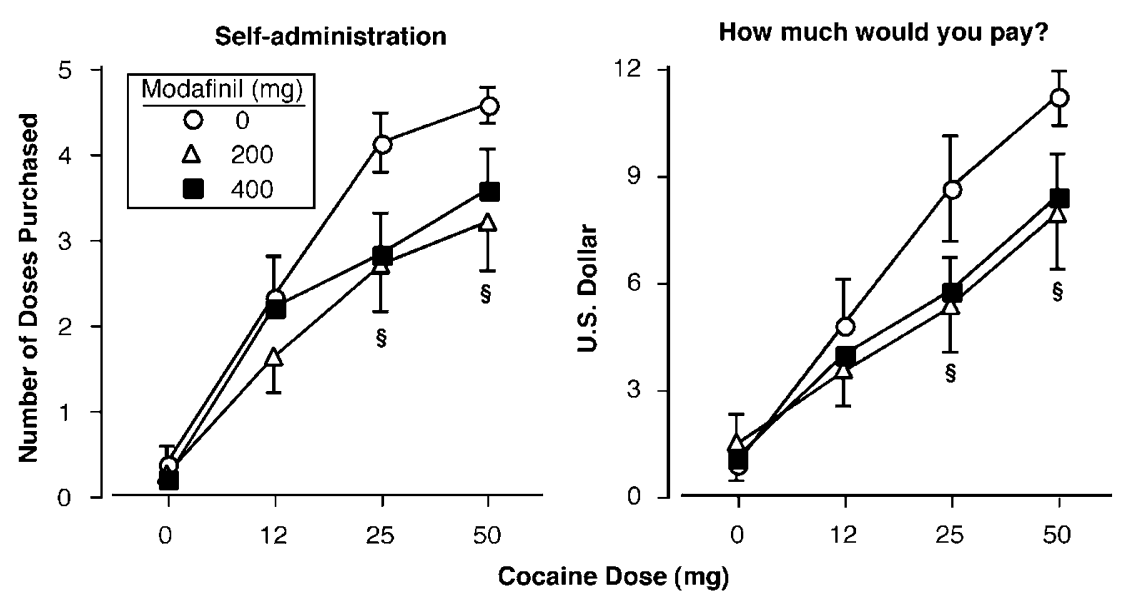

Figure I Left panel: mean number of cocaine doses purchased as a function of cocaine dose and modafinil maintenance condition. Right panel: peak values for VAS ratings for estimates of monetary value of the cocaine dose as a function of cocaine dose and modafinil maintenance condition. A $\S$ indicates a significant difference between both active maintenance conditions and the placebo maintenance condition $(p<0.05)$. Error bars represent one SEM. Overlapping error bars were omitted for clarity.

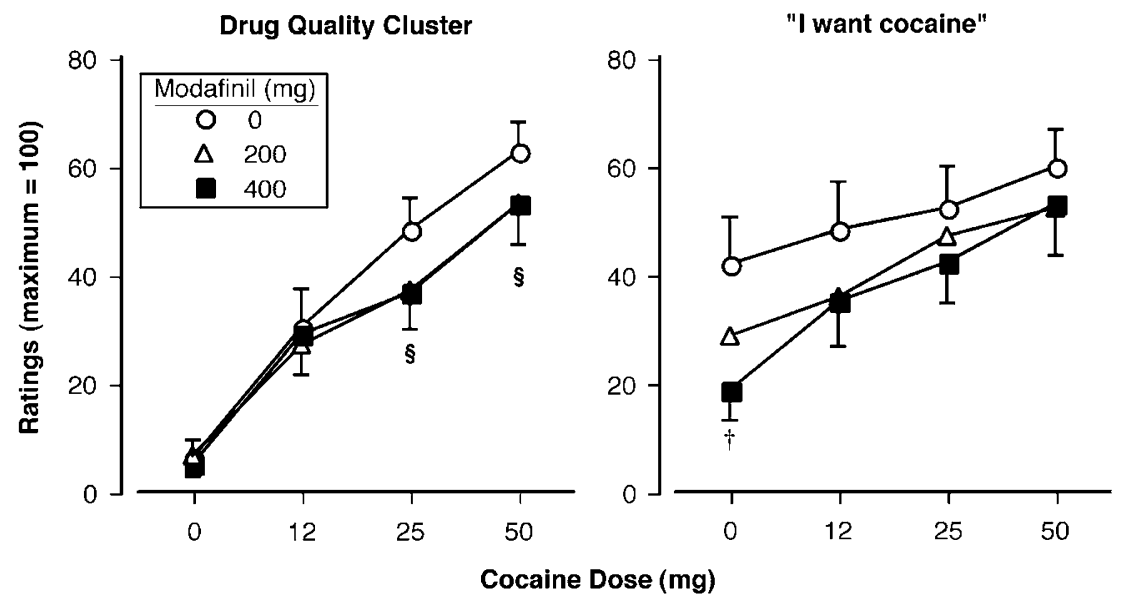

Figure 2 Peak values for VAS ratings on the 'Drug Quality' cluster and 'I want cocaine,' as a function of cocaine dose and modafinil maintenance condition. A $\S$ indicates a significant difference between both active maintenance conditions and the placebo maintenance condition $(p<0.05)$. A $\dagger$ indicates a significant difference between the $400 \mathrm{mg} /$ day maintenance condition and the placebo maintenance condition $(p<0.05)$. Error bars represent one SEM. Overlapping error bars were omitted for clarity.

the dose (Figure 1, right panel), $\mathrm{F}_{(3,42)}=8.64, p<0.002$. Some subjective effects of cocaine were significantly altered by modafinil maintenance. Similar to the selfadministration data, modafinil (200 and $400 \mathrm{mg}$ ) decreased the amount participants were willing to pay and ratings on the Drug Quality cluster following the 25- and 50-mg doses $(p<0.05)$. On average, modafinil decreased the amount participants were willing to pay for the larger cocaine doses by approximately $\$ 3$ (US). In addition, cocaine craving (operationalized using an 'I want cocaine' VAS item) was significantly decreased by $400 \mathrm{mg}$ modafinil following the 0 -mg cocaine dose ( $p<0.006$, Figure 2, right panel).

\section{Cardiovascular Effects}

Figure 3 shows cardiovascular measures as a function of cocaine dose and modafinil maintenance condition. Cocaine dose dependently increased peak $\operatorname{HR}\left(\mathrm{F}_{(3,42)}=\right.$ 42.16, $p<0.001)$, SP $\left(\mathrm{F}_{(3,42)}=37.16, p<0.001\right)$, and DP
$\left(\mathrm{F}_{(3,42)}=12.71, p<0.001\right)$. In general, modafinil significantly attenuated these cardiovascular elevations. Both active maintenance doses significantly decreased HR, SP, and DP following both larger cocaine doses ( 25 and $50 \mathrm{mg}, p<0.01$ ), with one exception. Modafinil did not significantly attenuate DP produced by the $50-\mathrm{mg}$ cocaine dose.

\section{Plasma Cocaine Levels}

Out of the 576 total possible blood samples during the inpatient portions of the study, $45(8 \%)$ were not completed due difficulties in accessing the participants' veins. Plasma cocaine levels were dose dependent and not affected by modafinil maintenance condition (data not shown).

\section{Plasma Modafinil Levels and Urine Fluorescence}

Blood samples for the measurement of plasma modafinil levels were drawn twice weekly during in-patient phases and 

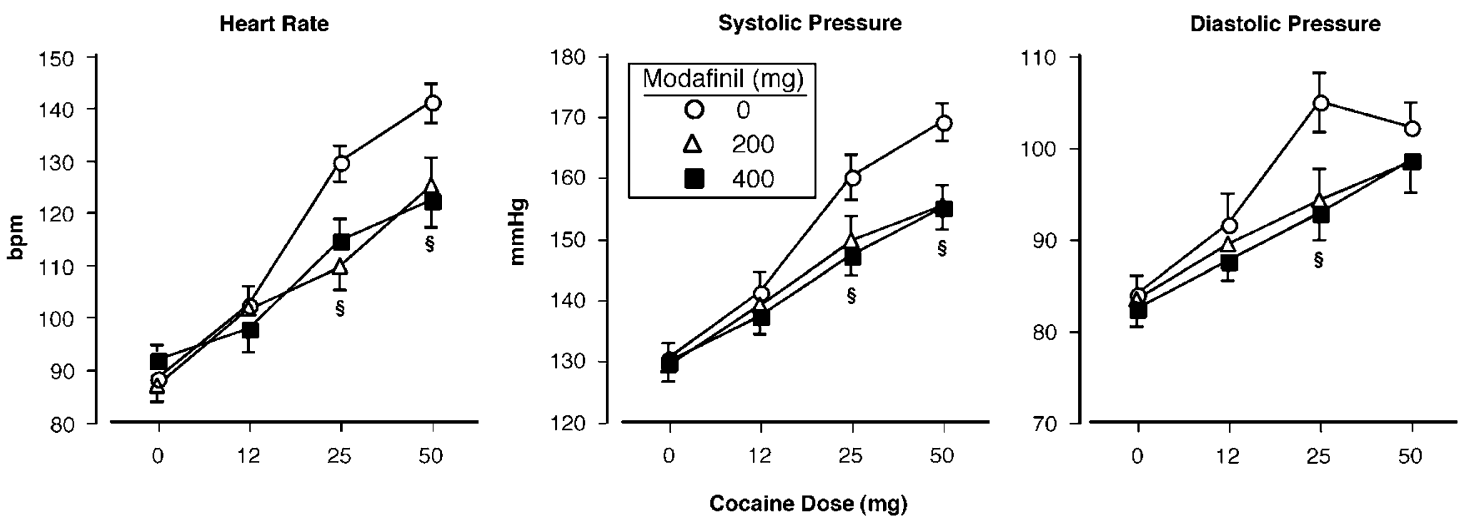

Figure 3 Peak values for heart rate, systolic pressure, and diastolic pressure as a function of cocaine dose and modafinil maintenance condition. A $\S$ indicates a significant difference between both active maintenance conditions and the placebo maintenance condition $(p<0.05)$. Error bars represent one SEM. Overlapping error bars were omitted for clarity.

once per each outpatient week. Mean \pm SD modafinil levels were as follows: $2.17 \pm 0.76 \mu \mathrm{g} / \mathrm{ml}$ (200 mg outpatient), $3.83 \pm 1.59 \mu \mathrm{g} / \mathrm{ml} \quad(200 \mathrm{mg} \quad$ in-patient $), \quad 6.20 \pm 2.25 \mu \mathrm{g} / \mathrm{ml}$ (400 mg outpatient), and $7.53 \pm 2.44 \mu \mathrm{g} / \mathrm{ml}(400 \mathrm{mg}$ inpatient). As expected, modafinil plasma levels were greater during the in-patient phases because the outpatient phases were used to crossover to another maintenance dose condition. All urine samples collected during outpatient phases were positive for riboflavin, as verified by ultraviolet fluorescence, suggesting good medication compliance.

\section{Cocaine-Positive Urines During Outpatient Phase}

Attendance at the outpatient visits was excellent: 41 of 42 scheduled visits were attended. There was no effect of modafinil on the number of urines that tested positive for cocaine in this group of nontreatment seekers, as 37 of 41 urines were positive for cocaine. Also, 6 of 41 urine samples tested positive for the marijuana metabolite $\Delta^{9}$-tetrahydrocannabinol.

\section{DISCUSSION}

The major finding from the present investigation was that modafinil (200 and $400 \mathrm{mg} /$ day) decreased cocaine selfadministration in a sample of nontreatment-seeking cocaine-dependent individuals. These are the first human laboratory data demonstrating that cocaine self-administration is markedly reduced during modafinil maintenance. The significance of this result is underscored by data from previous studies demonstrating that cocaine-taking behavior in this population is robust and extremely difficult to alter, even when 'positive' subjective responses to cocaine are decreased by a potential treatment medication (Haney et al, 1999; Foltin et al, 2003; Hart et al, 2004). The current data also show that cocaine-associated subjective-effect ratings and cardiovascular responses were significantly reduced when participants were maintained on modafinil. Modafinil doses produced equipotent effects on all measures. These results replicate and extend findings from human laboratory studies (Dackis et al, 2003; Malcolm et al, 2006) and are consistent with results from a clinical trial (Dackis et al, 2005) investigating cocaine use during modafinil treatment.

While the mechanism(s) mediating modafinil-related effects on cocaine self-administration is unknown, pharmacokinetic interactions between modafinil and cocaine can be excluded because plasma cocaine levels in the current study were unaffected by modafinil maintenance condition. Modafinil modulates the activity of CNS catecholamine transporters, which are established sites through which many of cocaine-related effects are mediated, so it is possible that this feature played a role in altering cocaine self-administration. Consistent with such a mechanism, modafinil is well absorbed after oral administration and has a terminal elimination half-life of approximately $12-15 \mathrm{~h}$ (Wong et al, 1999), whereas the half-life for cocaine is only about $1 \mathrm{~h}$. In addition, modafinil inhibits the firing of midbrain dopamine neurons, possibly through $\mathrm{D}_{2}$ autoreceptors (Korotkova et al, 2007). Thus, in the current study, it is conceivable that modafinil dampened the ability of the sampled dose of cocaine to acutely increase catecholamine transmission, and thereby reduced the perceived potency and subsequent choice to self-administer the drug. Other agonist mechanisms are also plausible as modafinil, like cocaine, increases glutamatergic activity and diminishes GABAergic transmission (Ferraro et al, 1997a, b, 1999; Cameron and Williams, 1994; Reid et al, 1997), and a combination of these neurochemical actions may have contributed to our findings. Such explanations are speculative, of course, and suggest avenues for future studies.

Modafinil attenuated several subjective effects of cocaine (eg cocaine craving and the amount participants were willing to pay for the dose sampled) and this is in line with results from previous laboratory studies that have assessed subjective response to cocaine in the presence of modafinil (Dackis et al, 2003; Malcolm et al, 2006). Note, however, that a decrease in the subjective effects of cocaine alone appears insufficient to account for the reduction in the number of cocaine doses purchased during modafinil maintenance. Data from a number of studies evaluating medications for the treatment of cocaine abuse show that cocaine-related positive subjective and reinforcing effects (self-administration) are dissociable (eg Foltin et al, 2003; Hart et al, 2004). Haney et al (1999), for example, reported 
that ABT-431, a selective agonist at the dopamine $D_{1}$ receptor, produced significant dose-dependent decreases in the subjective effects of cocaine, including ratings of 'high,' 'stimulated,' dose liking, estimates of dose value, 'quality,' and 'potency,' but it did not reduce cocaine self-administration. Fischman et al (1990) found a similar pattern of effects when they investigated the impact of desipramine maintenance on i.v. cocaine self-administration; these results were congruent with negative findings from followup clinical trials testing desipramine for efficacy as a pharmacotherapy for cocaine abuse. Several researchers reported that the medication did not decrease cocaine use, as measured by urine toxicology (Arndt et al, 1994; Campbell et al, 2003; McDowell et al, 2005). Indeed, this is consistent with the broader literature evaluating medications for utility in treating cocaine abuse. A number of medications examined have been shown to decrease the subjective effects of cocaine when tested under controlled laboratory conditions, but the decrease in subjective effects has failed to predict clinical utility (eg gabapentin; Hart et al, 2004; Bisaga et al, 2006). In contrast, the present results argue that clinical efficacy might be best predicted by a decrease in subjective effects and cocaine selfadministration in the laboratory.

Modafinil has a relatively benign side-effect profile and no clinically significant drug interactions (Wong et al, 1998; Hellriegel et al, 2001). Data from the current investigation are consistent with previous findings. The modafinilcocaine combination was well tolerated and did not produce additive cardiovascular effects. In fact, modafinil markedly attenuated cocaine-associated blood pressure and $\mathrm{HR}$ increases with the most pronounced effects being observed on HR and SP. Increases in HR and SP produced by the larger cocaine doses (25 and $50 \mathrm{mg}$ ) were significantly lessened by both maintenance modafinil doses. The pattern of effects obtained in this study is in agreement with findings from a recent investigation of cardiovascular and subjective responses to i.v. cocaine during modafinil maintenance. Malcolm et al (2006) reported that not only did modafinil decrease subjective effects of cocaine, but the drug also reduced cocaine-evoked increases in SP and HRs. Together, these data indicate that the drug combination does not increase cardiovascular toxicity and may offer protection to some of the cardiovascular effects of cocaine.

The present results should be interpreted within the context of at least two potential study limitations. All study participants were black and the overwhelming majority were males. While black cocaine abusers comprise about $50 \%$ of the individuals seeking treatment for smoked cocaine-related problems, a substantial proportion ( $\sim 50 \%)$ of smoked cocaine treatment-seekers are nonblack (SAMHSA, 2006). Similarly, female cocaine abusers represent about $40 \%$ of persons enrolled in treatment for smoked cocaine abuse. While it is possible that the characteristics of our sample may limit the generality of our findings, this seems unlikely because there is a dearth of data indicating that there are racial or sex differences in response to potential pharmacotherapies for cocaine abuse (but see, Evans and Foltin, 2006).

In conclusion, the current findings indicate that modafinil maintenance reduced cocaine-associated reinforcing, subjective, and cardiovascular effects without producing noticeable adverse consequences. The current overall pattern of effects is consistent with a developing body of research obtained in human cocaine abusers under both laboratory and clinical conditions. The data suggest that modafinil may have clinical utility as a treatment for cocaine dependence, although further study of the drug is needed to better understand the mechanism(s) underlying its therapeutic effects.

\section{ACKNOWLEDGEMENTS}

The nursing assistance of Brenda Fay and Alyce Stephens, and technical assistance of Catalina Saldaña and Martha Jacobs is gratefully acknowledged. This research was supported by Grant DA-006234 from the National Institute on Drug Abuse. Research participants resided on the Irving Center for Clinical Research of the Columbia Presbyterian Medical Center supported by Grant No. MOI-RR-00645 from the National Institutes of Health.

\section{DISCLOSURE/CONFLICT OF INTERESTS}

The authors declare that except for income received from my primary employer no financial support or compensation has been received from any individual or corporate entity over the past 3 years for research or professional service and there are no personal financial holdings that could be perceived as constituting a potential conflict of interests.

\section{REFERENCES}

Arndt IO, McLellan AT, Dorozynsky L, Woody GE, O’Brien CP (1994). Desipramine treatment for cocaine dependence. Role of antisocial personality disorder. J Nerv Ment Dis 182: 151-156.

Bardo MT (1998). Neuropharmacological mechanisms of the drug reward: beyond dopamine in the nucleus. Crit Rev Neurobiol 12: 37-67.

Bisaga A, Aharonovich E, Garawi F, Levin FR, Rubin E, Raby WN et al (2006). A randomized placebo-controlled trial of gabapentin for cocaine dependence. Drug Alcohol Depend 81: 267-274.

Cameron DL, Williams JT (1994). Cocaine inhibits GABA release in the VTA through endogenous 5-HT. J Neurosci 14: 6763-6767.

Campbell J, Nickel EJ, Penick EC, Wallace D, Gabrielli WF, Rowe C et al (2003). Comparison of desipramine or carbamazepine to placebo for crack cocaine-dependent patients. Am J Addict 12: $122-136$.

Dackis CA, Kampman KM, Lynch KG, Pettinati HM, O’Brien CP (2005). A double-blind, placebo-controlled trial of modafinil for cocaine dependence. Neuropsychopharmacology 30: 205-211.

Dackis CA, Lynch KG, Yu E, Samaha FF, Kampman KM, Cornish JW et al (2003). Modafinil and cocaine: a double-blind, placebocontrolled drug interaction study. Drug Alcohol Depend 70: 29-37.

Duteil J, Rambert FA, Pessonnier J, Hermant JF, Gombert R, Assous E (1990). Central alpha 1-adrenergic stimulation in relation to the behaviour stimulating effect of modafinil; studies with experimental animals. Eur J Pharmacol 180: 49-58.

Evans SM, Foltin RW (2006). Exogenous progesterone attenuates the subjective effects of smoked cocaine in women, but not in men. Neuropsychopharmacology 31: 659-674.

Evans SM, Haney M, Foltin RW (2002). The effects of smoked cocaine during the follicular and luteal phases of the menstrual cycle in women. Psychopharmacology 159: 397-406. 
Ferraro L, Antonelli T, O’Conner WJ, Tanganelli S, Rambert FA, Fuxe K (1997a). Modafinil: an antinarcoleptic drug with a different neurochemical profile to D-amphetamine and dopamine uptake blockers. Biol Psychiatry 42: 1181-1183.

Ferraro L, Antonelli T, O’Connor WT, Tanganelli S, Rambert F, Fuxe K (1997b). The antinarcoleptic drug modafinil increases glutamate release in thalamic areas and hippocampus. Neuroreport 8: 2883-2887.

Ferraro L, Antonelli T, Tanganelli S, O'Connor WT, Perez de la Mora M, Mendez-Franco J et al (1999). The vigilance promoting drug modafinil increases extracellular glutamate levels in the medial preoptic area and the posterior hypothalamus of the conscious rat: prevention by local GABAA receptor blockade. Neuropsychopharmacology 20: 346-356.

Fischman MW, Foltin RW, Nestadt G, Pearlson GD (1990). Effects of desipramine maintenance on cocaine self-administration by humans. J Pharmacol Exp Ther 253: 760-770.

Foltin RW, Fischman MW, Nestadt G, Stromberger H, Cornell EE, Pearlson GD (1990). Demonstration of naturalistic methods for cocaine smoking by human volunteers. Drug Alcohol Depend 26: $145-154$.

Foltin RW, Haney M (2004). Intranasal cocaine in humans: acute tolerance, cardiovascular and subjective effects. Pharmacol Biochem Behav 78: 93-101.

Foltin RW, Ward AS, Collins ED, Haney M, Hart CL, Fischman MW (2003). The effects of venlafaxine on the subjective, reinforcing and cardiovascular effects of cocaine in opioiddependent and non-opioid-dependent humans. Exp Clin Psychopharmacol 11: 123-130.

Haney M, Collins ED, Ward AS, Foltin RW, Fischman MW (1999). Effect of a selective dopamine D1 agonist (ABT-431) on smoked cocaine self-administration in humans. Psychopharmacology 143: $102-110$.

Hart CL, Haney M, Collins ED, Rubin E, Foltin RW (2007a). Smoked cocaine self-administration by humans is not reduced by large gabapentin maintenance doses. Drug Alcohol Depend 86: $274-277$.

Hart CL, Haney M, Vosburg SK, Rubin E, Foltin RW (2007b). Gabapentin does not reduce smoked cocaine self-administration: employment of a novel self-administration procedure. Behav Pharmacol 18: 71-75.

Hart CL, Lynch WJ (2005). Developing pharmacotherapies for cannabis and cocaine use disorders. Curr Neuropharmacol 3: 95-114.

Hart CL, Ward AS, Collins ED, Haney M, Foltin RW (2004). Gabapentin maintenance decreases smoked cocaine-related subjective effects, but not self-administration by humans. Drug Alcohol Depend 73: 279-287.

Hellriegel ET, Arora S, Nelson M, Robertson P (2001). Steady-state pharmacokinetics and tolerability of modafinil given alone or in combination with methylphenidate in healthy volunteers. J Clin Pharmacol 41: 895-904.
Isenschmid DS, Fischman MW, Foltin RW, Caplan YH (1992). Concentration of cocaine and metabolites in plasma of humans following intravenous administration and smoking of cocaine. J Anal Toxicol 16: 311-314.

Korotkova TM, Klyuch BP, Ponomarenko AA, Lin JS, Haas HL, Sergeeva OA (2007). Modafinil inhibits rat midbrain dopaminergic neurons through D2-like receptors. Neuropharmacology 52: 626-633.

Lin JS, Roussel B, Akaoka H, Fort P, Debilly G, Jouvet M (1992). Role of catecholamines in the modafinil and amphetamine induced wakefulness, a comparative pharmacological study in the cat. Brain Res 591: 319-326.

Madras BK, Xie Z, Lin Z, Panas H, Lynch L, Johnson R et al (2006). Modafinil occupies dopamine and norepinephrine transporters in vivo and modulates the transporters and trace amine activity in vitro. J Pharmacol Exp Ther 319: 561-569.

Malcolm R, Swayngim K, Donovan JL, Devane CL, Elkashef A, Chiang $\mathrm{N}$ et al (2006). Modafinil and cocaine interactions. Am J Drug Alcohol Abuse 32: 577-587.

McDowell D, Nunes EV, Seracini AM, Rothenberg J, Vosburg SK, Ma GJ et al (2005). Desipramine treatment of cocaine-dependent patients with depression: a placebo-controlled trial. Drug Alcohol Depend 80: 209-221.

Mignot E, Nishino S, Guilleminault C, Dement WC (1994). Modafinil binds to the dopamine uptake carrier site with low affinity. Sleep 17: 436-437.

Reid MS, Hsu Jr K, Berger SP (1997). Cocaine and amphetamine preferentially stimulate glutamate release in the limbic system: studies on the involvement of dopamine. Synapse 27: 95-105.

Sofuoglu M, Kosten TR (2006). Emerging pharmacological strategies in the flight against cocaine addiction. Expert Opin Emerg Drugs 11: 91-98.

Substance Abuse and Mental Health Services Administration, Office of Applied Studies (2006). Treatment Episode Data Set (TEDS). Highlights-2005. National Admissions to Substance Abuse Treatment Services, DASIS Series: S-36, DHHS Publication No. (SMA) 07-4229, Rockville, MD.

Vocci F, Ling W (2005). Medications development: successes and challenges. Pharmacol Ther 108: 94-108.

Wisor JP, Eriksson KS (2005). Dopaminergic-adrenergic interactions in the wake promoting mechanism of modafinil. Neuroscience 132: 1027-1034.

Wong YN, Simcoe D, Hartman LN, Laughton WB, King SP, McCormick GC et al (1999). A double-blind, placebo-controlled, ascending-dose evaluation of the pharmacokinetics and tolerability of modafinil tablets in healthy male volunteers. J Clin Pharmacol 39: 30-40.

Wong YN, Wang L, Hartman L, Simcoe D, Chen Y, Laughton W et al (1998). Comparison of the single-dose pharmacokinetics and tolerability of modafinil and dextroamphetamine administered alone or in combination in healthy male volunteers. J Clin Pharmacol 38: 971-978. 